\title{
DESIGN, PREPARATION, AND EVALUATION OF SELF-MICROEMULSIFYING DRUG DELIVERY SYSTEM OF BAMBUTEROL HYDROCHLORIDE
}

\author{
SACHIN SAGGAR ${ }^{1 *}$, ASHUTOSH UPADHAYAY ${ }^{2}$, MANISH GOSWAMI $^{3}$ \\ 1,2 Department of Pharmaceutical Sciences, MJRP College of Health Care \& Allied Sciences, Mahatma Jyoti Rao Phoole University, Jaipur, \\ Rajasthan, India. ${ }^{3}$ Department of Pharmaceutical Sciences, University Institute of Pharma Sciences, Chandigarh University, Mohali \\ Punjab, India. Email: sachinsaggar@yahoo.com
}

Received: 01 June 2018, Revised and Accepted: 09 August 2018

ABSTRACT

Objective: The self-micro-emulsifying drug delivery system (SMEDDS) of bambuterol hydrochloride was designed, prepared, and evaluated to overcome the problem of poor bioavailability.

Methods: The designing of the formulation included the selection of oil phase, surfactant, and cosolvent/cosurfactant based on the saturated solubility studies. Psuedoternary phase diagram was constructed using aqueous titration method, to identify the self-emulsifying region. Different ratios of the selected surfactant and cosolvent/cosurfactant (Smix) were also studied and used to construct the ternary phase diagram. The prepared formulations of the SMEDDS were evaluated for drug content, morphology, globule size, robustness to dilution, emulsification time, optical clarity, and stability.

Results: The formulation containing $10 \mathrm{mg}$ bambuterol hydrochloride, triacetin ( $12.50 \% \mathrm{w} / \mathrm{w})$, Tween 80 (43.75\% w/w), and ethanol (43.75\% w/w) was concluded to be optimized. The optimized SMEDDS not only showed optimum globule size, zeta potential, and drug content but was also found to be robust to dilution, formed emulsion spontaneously, and was stable. The optimized SMEDDS showed increased permeability of the drug across the intestinal membrane in ex vivo studies.

Conclusion: The results suggest that bambuterol hydrochloride can be formulated as self-microemulsifying drug delivery system, and further, SMEDDS can be used to improve the oral bioavailability of bambuterol hydrochloride.

Keywords: Self-microemulsifying drug delivery system, Bambuterol hydrochloride, Phase diagram, Zetasizer, Everted gut technique.

(C) 2018 The Authors. Published by Innovare Academic Sciences Pvt Ltd. This is an open access article under the CC BY license (http://creativecommons. org/licenses/by/4. 0/) DOI: http://dx.doi.org/10.22159/ajpcr.2018.v11i12.27890

\section{INTRODUCTION}

Self-emulsifying drug delivery system (SEDDS) refers to a formulation comprising an isotropic mixture of natural and synthetic oils with hydrophilic or lipophilic surfactants and cosolvent(s) which spontaneously emulsifies when exposed to the gastrointestinal fluid to form oil-in-water emulsion [1-4]. The emulsion so produced is a clear dispersion in which the particle size of the dispersed phase ranges from nanometers to several microns. In case of microemulsions, the average diameter of the dispersed phase is in size range of $10-100 \mathrm{~nm}$, whereas in nanoemulsions, droplet size is in the range of $50-1000 \mathrm{~nm}$ (preferably from 100 to $500 \mathrm{~nm}$ ). The main difference between microemulsions and nanoemulsions is regarding their physical stability, appearance, and microstructure [5]. On peroral administration, SEDDS form fine emulsions (or microemulsions) in the gastrointestinal tract (GIT) with mild agitation provided by gastric mobility [6,7]. The difference between a SEDDS and self-microemulsifying drug delivery system (SMEDDS) is that the former when diluted results in a droplet size between 100 and $300 \mathrm{~nm}$ and the latter result in a droplet size of $<50 \mathrm{~nm}$ [8].

SEDDS can overcome the problems associated with various drugs falling in various Biopharmaceutical Classification System (BCS) classes, and in case of BCS Class III drugs, SEDDS can overcome the problem of enzymatic degradation, gut wall efflux, and bioavailability [9].

The presence of the lipids in the formulation leads to the delay in the gastric emptying, resulting in the increase in the gastric residence time. Therefore, the drug remains for prolong time in the GIT which enables better dissolution of the drug at the absorption site and therefore increases the absorption [10]. In the presence of the increased bile salt concentration, the breakdown product of the lipids digestion is incorporated into series of colloidal structure such as micelles which increases the solubilization capacity of the small intestine for the lipid-digested product and the drug $[10,11]$.

A number of lipids have shown the ability to alter the permeability of the gut wall and increase the permeability of the intestine [12]. Lipids may enhance the extent of lymphatic transport and increase the bioavailability directly or indirectly by reduction in first-pass metabolism. Certain lipids and surfactants have shown the tendency to reduce the activity of the efflux transporters in the GI wall, thereby increasing the amount of drug absorbed. This mechanism may also lead to reduced intraenterocyte metabolism since there is an interplay between P-gp and CYP3A4. Cremophor EL, Labrasol, Polysorbate 80, and Polysorbate 20 have shown P-gp inhibitory activity [13]

Bambuterol hydrochloride is 5-[(1RS)-2-[(1,1-dimethylethyl) amino]-1-hydroxyethyl]-1,3-phenylene bis(dimethylcarbamate) hydrochloride [14]. Bambuterol is a long-acting $\beta$-2 adrenoceptor agonist used in the treatment of asthma. It is a prodrug of terbutaline. Bambuterol causes smooth muscle relaxation, resulting in dilation of bronchial passages. It is freely soluble in water [14]. On average, $20 \%$ of an oral dose is absorbed. Protein binding of bambuterol is low, $40-50 \%$ at therapeutic concentrations. The terminal half-life of bambuterol after an oral dose is $9-17 \mathrm{~h}$. Bambuterol is metabolized in the liver, and terbutaline is formed by both hydrolysis and oxidation. After absorption from the gut, about two-third of absorbed bambuterol survives first-pass metabolism, and rest third is metabolized to intermediary metabolites which are still prodrugs of terbutaline. Terbutaline has a bioavailability of about $10 \%$ of administered dose $[15,16]$. Renal clearance after oral administration is around $1250 \mathrm{~mL} / \mathrm{min}$. 
Bambuterol is available as $10 \mathrm{mg}$ and $20 \mathrm{mg}$ tablet for oral administration. The dosage of bambuterol is $10 \mathrm{mg}$ per day, but it may also be administered up to $20 \mathrm{mg}$ per day. Bambuterol is also available in the liquid dosage form in the strength of $1 \mathrm{mg} / \mathrm{mL}$ and $2 \mathrm{mg} / \mathrm{mL}$.

In this study, SMEDDS of bambuterol has been prepared by ultrasonication method. The main purpose behind choosing SMEDDS formulation for bambuterol was that lipid-based formulation enhances the permeability of the drug, thereby increasing the bioavailability of the drug. Moreover, the side effects such as tremors associated with $\beta$-2 agonists are dose dependent. Hence, the aim of the present study was to develop the SMEDDS of bambuterol to enhance its bioavailability which may lead to the reduction in dose and side effect of the drug.

\section{MATERIALS AND METHODS}

\section{Materials}

Bambuterol hydrochloride was purchased from Yarrow Chem Products, Mumbai. Tween 80 was gifted by Eden drugs Pvt. Ltd., Amritsar. Triacetin was gifted by Alkon Lab., Amritsar. Distilled water, hydrochloric acid (Ramkem LR grade), potassium chloride (Qualigens AR grade), potassium dihydrogen phosphate (CDH LR), disodium hydrogen phosphate, sodium chloride (S.D. Fine chem., extra pure), and ethanol (Changshu Hongsheng Fine Chemical, AR) were used in the study.

\section{Methods}

\section{Solubility of bambuterol in oil, surfactant, and cosolvent}

The solubility of the bambuterol in various oils (isopropyl myristate, triacetin, oleic acid, ethyl oleate, and labrafil 1944), surfactant (Tween 80, labrasol, and cremophor EL), and cosolvent/cosurfactant (propylene glycol [PG], polyethylene glycol 400, ethanol, and transcutol) was determined by dissolving excess amount of drug in $3 \mathrm{~mL}$ of each of selected oil, surfactant, and cosolvent/cosurfactant in a $5 \mathrm{~mL}$ stoppered vial. The excess amount of drug was mixed using a vortex mixer. The vials were then kept at $37 \pm 1^{\circ} \mathrm{C}$ in an isothermal shaker for $72 \mathrm{~h}$ to get to equilibrium. The equilibrated samples were then centrifuged at $3000 \mathrm{rpm}$ for $15 \mathrm{~min}$. The supernatant of the centrifuged samples was carefully separated/removed with the help of syringe and needle without disturbing the precipitated portion of the samples. The concentration of the drug in each of the samples was estimated by diluting the samples with isopropyl alcohol and measuring the absorbance at $265 \mathrm{~nm}$ using (UV 1800 Shimadzu, Japan) ultraviolet spectrophotometer [17-21].

\section{Construction of pseudoternary phase diagram}

Pseudoternary phase diagrams were constructed to identify the regions such as o/w microemulsion or nanoemulsion, coarse emulsion, and gel/ viscous region by diluting specific oil/surfactant/cosolvent/cosurfactant mixture with water. The phase diagram is helpful to determine the appropriate concentration range and ratios of the components that can result in micro or nanoemulsion. The phase diagrams were constructed using aqueous titration method or spontaneous emulsification method. First of all, various ratios of surfactant and cosolvent/cosurfactant were prepared by mixing selected surfactant and selected cosolvent/ cosurfactant in various proportions such as $1: 1,1: 2$, and $1: 3 \mathrm{w} / \mathrm{w}$. The mixture of surfactant and cosolvent/cosurfactant is termed as Smix. Thereafter, different types of Smix were mixed with selected oil in ratios of 9:1, 8:2, 7:3, 6:4, 5:5, 4:6, 3:7, 2:8, and 1:9 w/w in a glass vial at room temperature by vortexing for at least $5 \mathrm{~min}$. Each ratio of Smix mixed with oil was then titrated with distilled water in increments of $25 \mu \mathrm{L}$ of water using a micropipette, and the sample was vigorously mixed by vortexing for at least $2 \mathrm{~min}$ and then kept at room temperature for $10 \mathrm{~min}$ to reach equilibrium before next addition of water. The process was repeated either until the sample turned turbid or until $90.90 \% \mathrm{w} / \mathrm{w}$ addition of water. The phase behavior of each ternary phase system was minutely observed during the titration. The percentage composition of each component in the ternary system was determined, and the results were plotted on the triangular coordinates to construct the phase diagram $[22,23]$.
The same process was repeated with all the other ratios of surfactant and cosurfactant.

Pseudoternary phase diagram was constructed using Triplot software.

\section{Preparation of SMEDDS}

The amount of the oil, surfactant, and cosolvent/cosurfactant to be taken was decided on the basis of microemulsification region in the ternary phase diagram. Bambuterol hydrochloride was accurately weighed and dissolved in the required quantity of oil and Smix (surfactant and co-solvent/co-surfactant), taken in a screw-capped glass vial by sonicating at $37^{\circ} \mathrm{C}$ for maximum up to $30 \mathrm{~min}$. Thirteen formulations each containing different concentrations of oil, surfactant, and cosurfactant were prepared. Each formulation contained $10 \mathrm{mg}$ of bambuterol hydrochloride.

Physiochemical characterization/evaluation of SMEDDS [17-21,24] Emulsification time

Emulsification time is the time taken by the preconcentrate to form a homogeneous mixture on dilution. It was monitored by visual observation. In this method, $1 \mathrm{~g}$ of each preconcentrate containing bambuterol hydrochloride equivalent to $10 \mathrm{mg}$ was diluted to $100 \mathrm{~mL}$ distilled water with the help of magnetic stirrer $\left(100 \mathrm{rpm}\right.$ at $\left.37^{\circ} \mathrm{C}\right)$, and time taken to form microemulsion was observed. The studies were done in triplicate $[20,24,25]$.

\section{Globule size determination}

$1 \mathrm{~g}$ of each preconcentrate containing bambuterol hydrochloride equivalent to $10 \mathrm{mg}$ was diluted with $100 \mathrm{~mL}$ of distilled water in a volumetric flask and was sonicated at $37^{\circ} \mathrm{C}$ for $10 \mathrm{~min}$. The sample was allowed to equilibrate for $15 \mathrm{~min}$ and the droplet size of the resultant microemulsion was determined by photon correlation spectroscopy that analyzes the fluctuation in the light scattering due to the Brownian motion of droplets as a function of time using Zetasizer Nano Series (Beckman Coulter-Delsa Nano). The same process was repeated with $0.1 \mathrm{~N}$ hydrochloric acid [17-20,24].

\section{Zeta potential}

The emulsion stability is directly related to the magnitude of the surface charge. The zeta potential of the diluted SMEDDS formulation used for globule size measurement was measured using a Zetasizer (Beckman Coulter-Delsa Nano). The SMEDDS was diluted with distilled water $[17-20,24]$.

\section{Visual assessment and robustness to dilution}

Robustness to dilution was studied by diluting $1 \mathrm{~g}$ of the preconcentrate containing bambuterol hydrochloride equivalent to $10 \mathrm{mg}$ with $100 \mathrm{~mL}$ distilled water, $0.1 \mathrm{~N}$ hydrochloric acid, and $\mathrm{pH} 6.8$ buffer with the help of magnetic stirrer $\left(100 \mathrm{rpm}\right.$ at $\left.37^{\circ} \mathrm{C}\right)$ and the resultant dilution was kept for $24 \mathrm{~h}$ at room temperature for observation. The SMEDDS was graded from Grade I to Grade IV on the basis of their physical appearance based on visual assessment of the microemulsion formed on dilution. The emulsion formed on dilution may vary from clear to milky in appearance. The studies were done in triplicate $[18-20,25,26]$.

\section{Percentage transmission/optical clarity}

$1 \mathrm{~g}$ of each preconcentrate containing bambuterol hydrochloride equivalent to $10 \mathrm{mg}$ was diluted with $100 \mathrm{~mL}$ of distilled water in a beaker with help of magnetic stirrer $\left(100 \mathrm{rpm}\right.$ at $\left.37^{\circ} \mathrm{C}\right)$. Percentage transmission of each dispersion was measured at $400 \mathrm{~nm}$ using UV spectrophotometer at $0 \mathrm{~h}, 12 \mathrm{~h}$, and $24 \mathrm{~h}$. The studies were done in triplicate $[24,26]$.

\section{Cloud point test}

$1 \mathrm{~g}$ of the preconcentrate was diluted to $250 \mathrm{~mL}$ with distilled water, the resultant dilution was placed on a water bath, and the temperature of 
the water bath was gradually increased from $35^{\circ} \mathrm{C}$ to $100^{\circ} \mathrm{C}$. The cloud point was measured at the temperature at which there was sudden appearance of cloudiness. The studies were done in triplicate $[18,25,26]$.

\section{Viscosity}

$20 \mathrm{~g}$ of each preconcentrate was weighed and transferred to a beaker, and viscosity of the formulation was determined with the help of Fungilab-viscolead-Pro viscometer, spindle-PC at 12, 6, and $2 \mathrm{rpm}$ for 5 min. Viscosity measurement was done in triplicate [18].

\section{Refractive index}

Refractive index of preconcentrate loaded with drug and preconcentrate without drug was determined using Abbe's type refractometer. Refractive index measurement was done in triplicate [20]

\section{Drug content}

Bambuterol hydrochloride was extracted from the SMEDDS in pH 6.8 buffer using ultrasonication technique. The solutions of SMEDDS were sonicated for $10 \mathrm{~min}$ at $37^{\circ} \mathrm{C}$ and then allowed to equilibrate for another $10 \mathrm{~min}$. Thereafter, the solutions were filtered through Whatman filter paper. The filtrates were analyzed for content of bambuterol hydrochloride using UV spectrophotometric technique at $264 \mathrm{~nm}$. Drug content estimation studies were done in triplicate $[17,19,24]$.

\section{Stability studies}

Stability of the formulations (shelf life) as a function of time and storage temperature was evaluated by visual inspection of the self-emulsifying drug delivery system at different time periods up to 6 months. The parameters evaluated for stability studies by visual inspection included phase separation, precipitation of the drug, or any other excipients. Each preconcentrate containing $10 \mathrm{mg}$ of the drug, bambuterol hydrochloride, was diluted with distilled water to form $5 \mathrm{~g}$ formulation. The dilution was done as per the ratios of all the three components (oil, Smix, and water) obtained from the phase diagram. Similarly, preconcentrate without drug was also diluted with distilled water to form $5 \mathrm{~g}$ formulation, and this formulation was to act as blank and was useful in comparison.

$5 \mathrm{~g}$ of each formulation containing bambuterol hydrochloride equivalent to $10 \mathrm{mg}$ was stored in a well-closed container at room conditions for 6 months. Similarly, $5 \mathrm{~g}$ of each formulation without bambuterol hydrochloride was also stored in a well-closed container at room conditions for 6 months. The formulations were periodically checked for any precipitation/sedimentation, phase separation, and any other changes.

In another stability study, $10 \mathrm{mg}$ of the drug bambuterol hydrochloride was dissolved in each preconcentrate and was stored in a well-closed container at room conditions for 6 months. Similarly, preconcentrate without bambuterol hydrochloride was also stored in a well-closed container at room conditions for 6 months. The formulations were periodically checked for any precipitation/sedimentation, phase separation, and any other changes.

These studies were also useful in comparing the stability of the SMEDDS and the microemulsion, up to 6 months [20].

\section{Thermodynamic stability studies}

\section{Heating and cooling cycle/stability testing}

Each preconcentrate containing $10 \mathrm{mg}$ of the drug, bambuterol hydrochloride, was diluted with distilled water to form $5 \mathrm{~g}$ formulation, as mentioned above. $5 \mathrm{~g}$ of each formulation was then subjected to six cycles between refrigerated temperatures $4^{\circ} \mathrm{C}$ and $25 \pm 1^{\circ} \mathrm{C}$ (since formulation contains ethanol which has a flash point below $45^{\circ} \mathrm{C}$, hence the stability testing was performed at temperatures around $25^{\circ} \mathrm{C}$ ) with storage at each temperature for not $<48 \mathrm{~h}$. The formulations which were stable at these temperatures were subjected to centrifuge test.

\section{Centrifuge test}

Passed formulations were centrifuged at $3500 \mathrm{rpm}$ for $30 \mathrm{~min}$ using a digital centrifuge $[18,20,25]$.

\section{Comparative ex vivo intestinal permeability studies}

The everted gut technique was employed for the ex vivo intestinal permeability studies. Fresh intestine of chicken was taken, and from the intestine, 5-6 cm long portion of ileum was removed and washed thoroughly and then everted immediately. The removed portion of ileum was checked for leaks by filling it with $0.9 \% \mathrm{w} / \mathrm{v}$ normal saline solution. The ileum was then suspended/hanged in a beaker filled with Krebs-Ringer phosphate buffer $(\mathrm{pH}$ 7.2-7.4) in "U-shaped" manner in such a way that both the ends of the ileum were available for withdrawing and replenishing the sample. Thereafter, bambuterol hydrochloride dissolved in preconcentrate was introduced in the beaker with stirring. The system was maintained at $37 \pm 1^{\circ} \mathrm{C}$ and stirred at $50 \mathrm{rpm}$ with the help of magnetic stirrer. The ileum was filled with $5 \mathrm{~mL}$ of Krebs-Ringer phosphate buffer (pH 7.2-7.4). $2 \mathrm{~mL}$ of sample was withdrawn from the ileum with the help of syringe at predetermined intervals, and the amount withdrawn from the ileum was immediately replenished to maintain sink condition. Samples were withdrawn up to $2 \mathrm{~h}$. The drug content in each of the samples was determined by UV Spectrophotometric method $[24,27]$.

The whole process was repeated by replacing SMEDDS formulation with bambuterol hydrochloride dissolved in distilled water. The amount of drug permeating across the membrane/intestine for the drug in solution and the drug in SMEDDS was compared.

The intestinal permeability is one of the major factors that govern the rate and extent of absorption [28].

\section{Statistical analysis}

Origin 9.0 software was used for statistical analysis. Where the studies have been done in triplicate, the data represent the mean \pm standard deviation. The statistical analysis was performed using student's t-test. A difference below the probability level was considered as statistically significant $(\mathrm{p}<0.05)$

\section{RESULTS AND DISCUSSION}

\section{Solubility studies}

To develop a good self-emulsifying drug delivery system, the drug should have a sufficient/good solubility in the oil, surfactant, and cosolvent/cosurfactant system. Bambuterol showed maximum solubility in triacetin $(635.12 \pm 4.88 \mu \mathrm{g} / \mathrm{mL})$ (Fig. 1) compared to other oils evaluated for solubility, and similarly, bambuterol showed maximum solubility in Tween $80(14.05 \pm 0.697 \mathrm{mg} / \mathrm{mL})$ (Fig. 2) compared to other surfactant and in ethanol $(26.538 \pm 3.135 \mathrm{mg} /$ $\mathrm{mL}$ ) (Fig. 3) ( $<<0.05$, t-test) when compared to other cosolvents/ cosurfactant. Bambuterol hydrochloride also showed sufficient

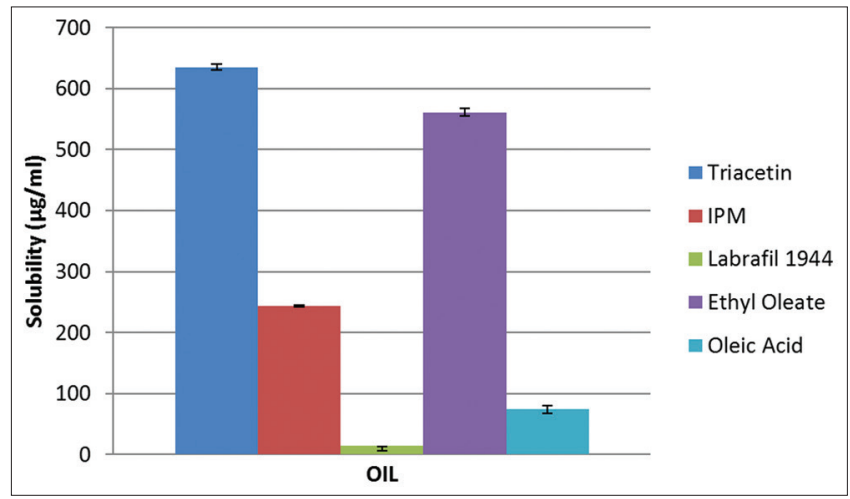

Fig. 1: Solubility chart of bambuterol hydrochloride in different oils (mean $\pm S D ; n=3$ ) 
solubility in PG $(9.464 \pm 0.260 \mathrm{mg} / \mathrm{mL})$; therefore, two systems one constituting triacetin, Tween 80 , and ethanol and another constituting triacetin, Tween 80, and PG were selected as oil, surfactant, and cosolvent/cosurfactant, respectively, for further studies.

\section{Construction of pseudoternary phase diagram}

The phase diagram was constructed using aqueous titration method or spontaneous emulsification method to identify the selfmicroemulsifying region. First of all, Smix was prepared by mixing Tween 80 and ethanol in following proportions 1:1, 2:1, 3:1, and $1: 2 \mathrm{w} / \mathrm{w}$, respectively. Thereafter, Smix was added to triacetin in ratios of 9:1, 8:2, 7:3, 6:4, 5:5, 4:6, 3:7, 2:8, and 1:9 w/w in a glass vial at room temperature, and the resultant mixture was vortexing for at least $5 \mathrm{~min}$.

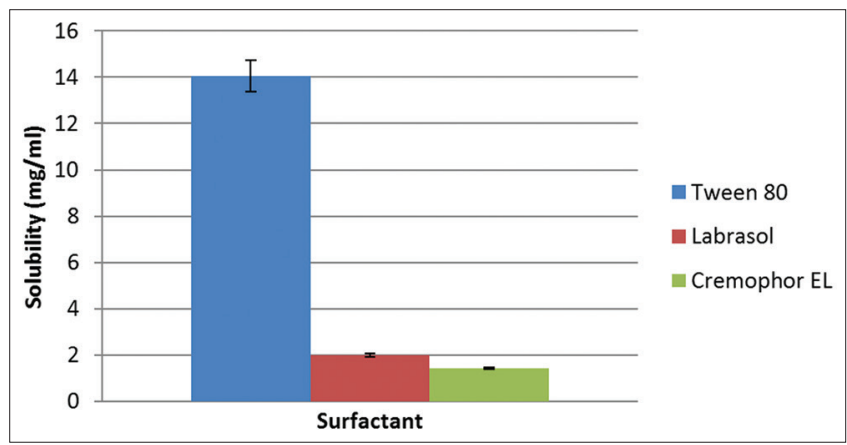

Fig. 2: Solubility chart of bambuterol hydrochloride in different surfactants (mean $\pm S D ; n=3$ )

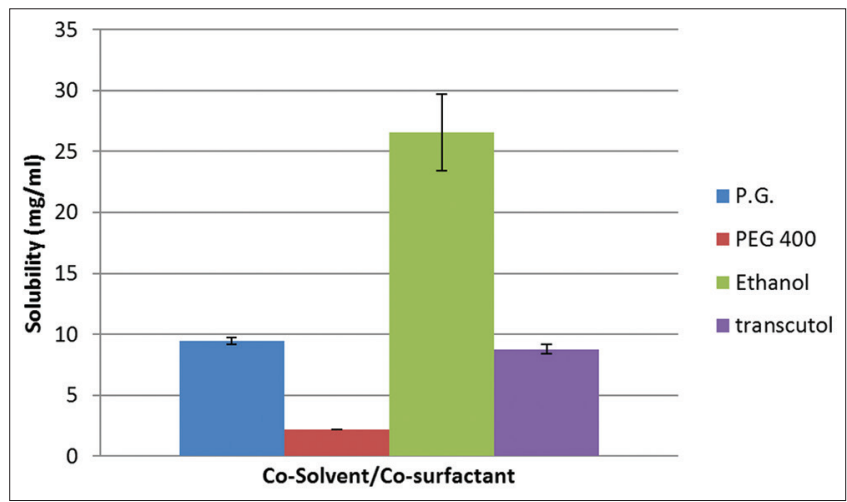

Fig. 3: Solubility chart of bambuterol hydrochloride in different cosolvents/cosurfactants (mean $\pm S D ; n=3$ )

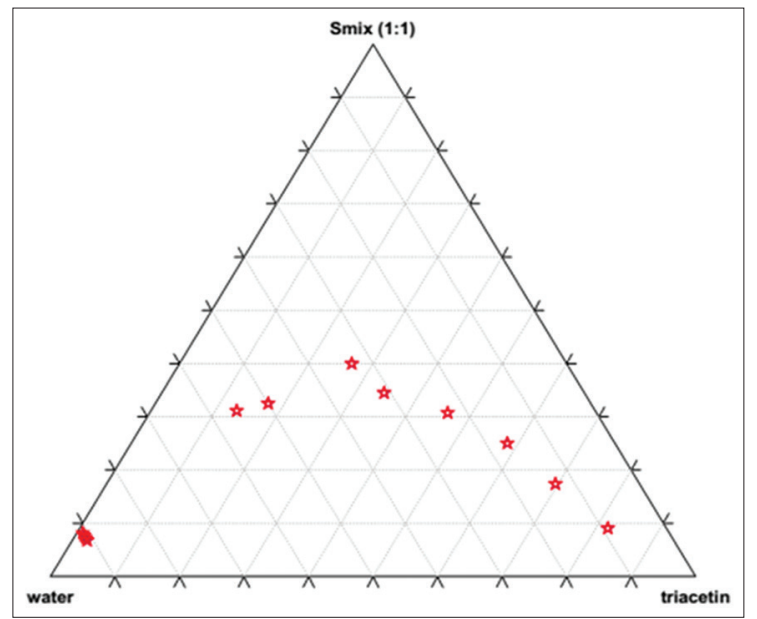

Fig. 4: Pseudoternary phase diagram of triacetin, Smix (Tween 80:ethanol [1:1]), and water
The Smix-triacetin mixture was then titrated with distilled water in increments of $25 \mu \mathrm{L}$ of water using a micropipette, and each sample was vigorously mixed by vortexing for at least $2 \mathrm{~min}$ and then kept at room temperature for $10 \mathrm{~min}$ to reach equilibrium before next addition of water. The process was repeated either until each sample turned turbid or till $90.90 \% \mathrm{w} / \mathrm{w}$ addition of water. The phase behavior of each ternary phase system was minutely observed during the titration. The percentage composition of triacetin, Tween 80 , ethanol, and water in the ternary system was determined, and the results were plotted on the triangular coordinates to construct the phase diagram. From the phase diagram, the percentage composition $\mathrm{w} / \mathrm{w}$ of triacetin, Tween 80, ethanol, and water that will form SMEDDS was determined. Smix prepared by mixing Tween 80 and ethanol in ratio 1:1,2:1, and 1:2 was selected for further studies, and Smix ratio 3:1 was rejected because the microemulsion region decreased with increase in the proportion of Tween 80 and was therefore not conducive for further studies (Figs. 4-6).

The same process was repeated with triacetin, Tween 80 , and PG. Smix was prepared by mixing Tween 80 and PG in following proportions 1:1, $2: 1$, and $1: 2 \mathrm{w} / \mathrm{w}$, respectively. Smix prepared by mixing Tween 80 and PG in ratio 1:1 and 1:2 was selected for further studies and Smix ratio $2: 1$ was rejected because the microemulsion region decreased with the increase of Tween 80 (Figs. 7 and 8).

Various formulations were prepared by mixing triacetin, Tween 80 , and ethanol in various percentage $\mathrm{w} / \mathrm{w}$ proportions. These formulations were further evaluated for various parameters including globule size and phase separation on storage. The same procedure was also adopted

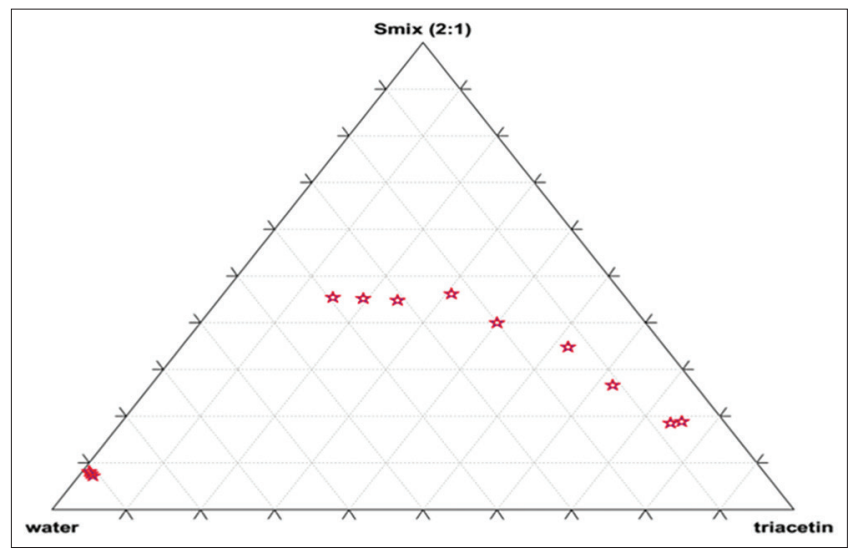

Fig. 5: Pseudoternary phase diagram of triacetin, Smix (Tween 80: ethanol [2:1]), and water

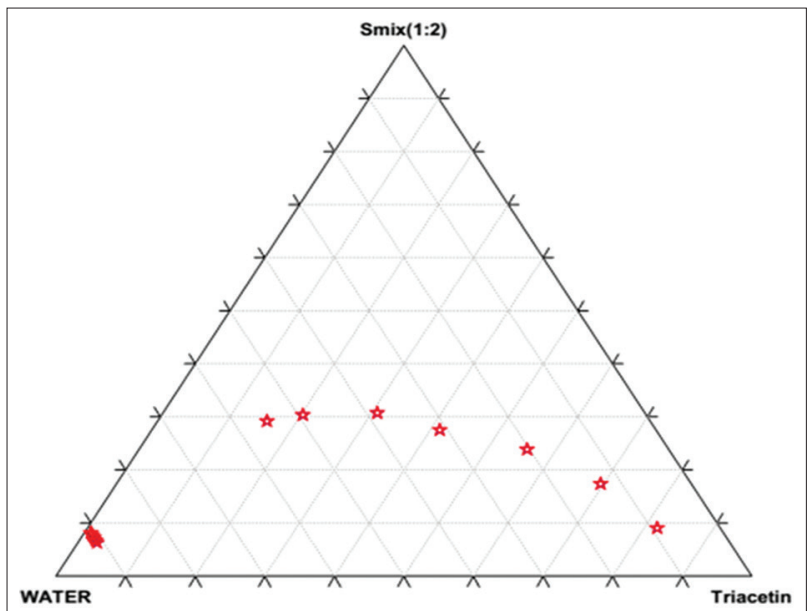

Fig. 6: Pseudoternary phase diagram of triacetin, Smix (Tween 80: ethanol [1:2]), and water 
for preparation and evaluation of formulations containing triacetin, Tween 80, and PG system.

On the basis of the phase diagram studies, 13 formulations/ compositions (Table 1) were selected for further studies.

\section{Preparation of SMEDDS}

Thirteen formulations (F1-F13) with different concentrations of oil, surfactant, and co-surfactant each containing $10 \mathrm{mg}$ of bambuterol

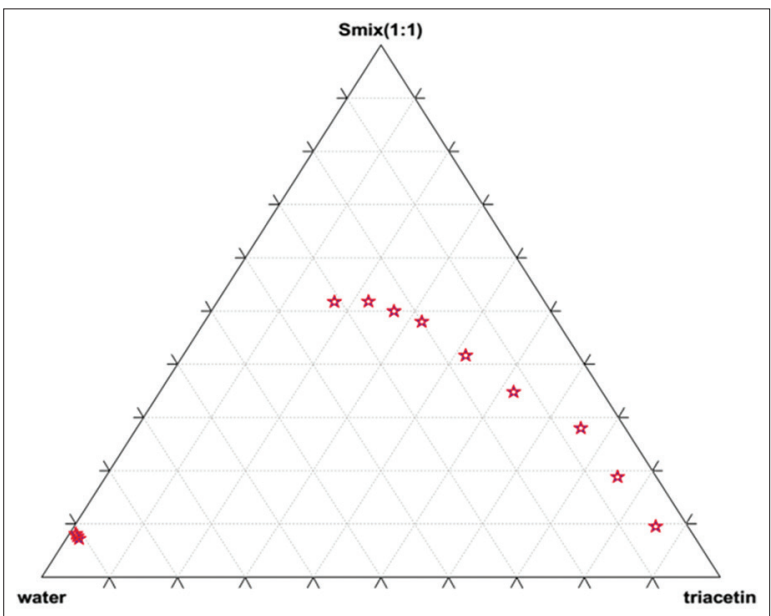

Fig. 7: Pseudoternary phase diagram of triacetin, Smix (Tween 80: PG [1:1]), and water

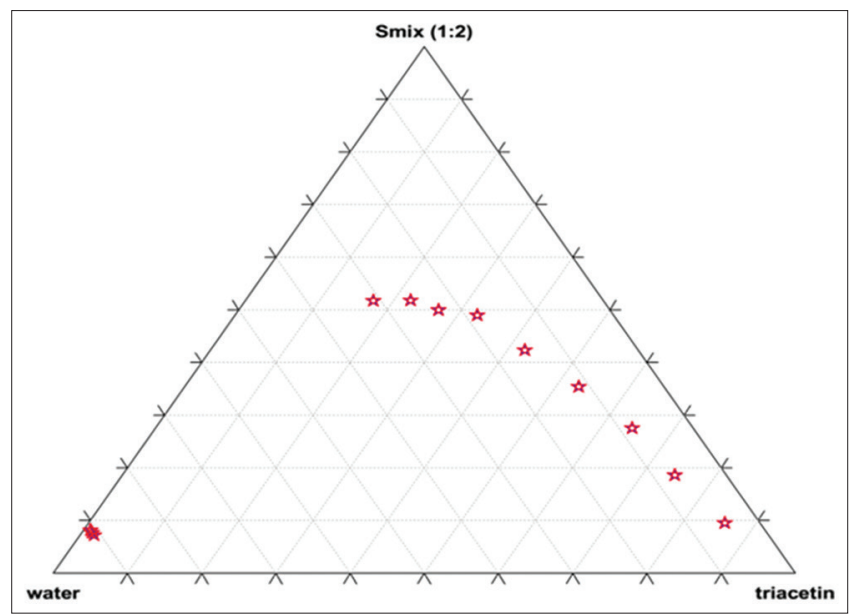

Fig. 8: Pseudoternary phase diagram of triacetin, Smix (Tween 80: PG [1:2]), and water hydrochloride were prepared by ultrasonication method and evaluated.

\section{Physiochemical characterization/evaluation of SMEDDS Emulsification time}

The efficiency of the emulsion can be determined by the emulsification time/rate of emulsification. The SMEDDS should disperse spontaneously and completely on dilution with distilled water under mild agitation. The emulsification time for all the 13 formulations was found to be $\leq 10 \mathrm{~s}$ (Table 2). This indicates that all the 13 SMEDDS formulations of bambuterol disperse spontaneously and completely on dilution. This can be attributed to the presence of surfactant systems which reduces interfacial tension between oil and water phases and enables rapid dispersion to form o/w emulsion. The studies were done in triplicate.

Globule size determination, polydispersity index (PDI), and zeta potential

The droplet size of the liquid SMEDDS is the most crucial factor in SMEDDS performance as it determines the rate and extent of drug release and absorption. Smaller droplet size will present a large area for drug absorption and hence increase bioavailability [3,29]. Increase in concentration of oil leads to an increase in globule size. The reduction in droplet size can be attributed to the stabilization of oil droplets due to the localization of surfactant monolayers at the oil-water interface [30]. The globule size of the SMEDDS in distilled water ranged from $14.5 \mathrm{~nm}$ to $1241.3 \mathrm{~nm}$. The lowest globule size was observed in SMEDDS F1, F2, F4, F5, F6, F7, F8, F10, and F11. The SMEDDS F4 and F5 also showed goods results, but since they contained a relatively high concentration of surfactant which can cause irritation of mucosa, therefore SMEDDS F1, F2, F6, F7, F10, and F11 were preferred over F4 and F5 (Table 3). In case of formulation F1-F9, it was observed that increase in ratio of oil resulted in proportionate increase in the droplet size. The presence of surfactants in the SMEDDS causes interfacial film to stabilize and condense, while cosurfactant causes the film to expand; thus, relative proportion of surfactant and co-surfactant has varied effects on the globule size [19].

Further, the globule size of SMEDDS in $0.1 \mathrm{~N}$ hydrochloric acid was also determined and it was found to be in the range of $14-89.1 \mathrm{~nm}$. This shows that the SMEDDS will produce droplet in microemulsion range in the gastric $\mathrm{pH}$ (Table 4).

The PDI of all the SMEDDSs ranged from 0.119 to 0.567 (Table 3), and the lowest PDI was reported for formulation F10. The PDI below 0.3 indicates good uniformity in the globule size distribution after dilution with water [31,32]. PDI of SMEDDS F1 was found to be 0.312 which indicates uniform globule distribution (Table 3).

Zeta potential of the SMEDDS in distilled water was found to be in the range of $+26.7 \mathrm{mV}$ to $-8.44 \mathrm{mV}$. In general, formulations having zeta

Table 1: Selected Composition at different \% w/w of oil, surfactant and co-surfactant for bambuterol SMEDDS

\begin{tabular}{|c|c|c|c|c|c|c|c|}
\hline \multirow[t]{2}{*}{ Composition Code } & \multirow[t]{2}{*}{ Smix } & \multirow[t]{2}{*}{ Smix Ratio } & \multicolumn{3}{|c|}{ Pre-concentrate } & \multirow[t]{2}{*}{ Oil:Smix } & \multirow[t]{2}{*}{ Precon.: water (for stability studies) } \\
\hline & & & Oil (parts) & Tween 80 (parts) & Ethanol (parts) & & \\
\hline F 1 & & 1:1 & 12.50 & 43.75 & 43.75 & $1: 7$ & 1:1.5 \\
\hline F 2 & Smix 1 & 1:1 & 13.80 & 43.10 & 43.10 & $1: 6.25$ & $1: 0.724$ \\
\hline F 3 & & $1: 1$ & 15.38 & 42.31 & 42.31 & $1: 5.5$ & $1: 0.538$ \\
\hline F 4 & & $2: 1$ & 12.50 & 58.33 & 29.17 & $1: 7$ & $1: 1.5$ \\
\hline F 5 & Smix 2 & $2: 1$ & 13.80 & 57.47 & 28.73 & $1: 6.25$ & $1: 0.724$ \\
\hline F 6 & & $2: 1$ & 15.38 & 56.41 & 28.20 & $1: 5.5$ & $1: 0.538$ \\
\hline F 7 & & $1: 2$ & 12.50 & 29.17 & 58.33 & $1: 7$ & $1: 1.5$ \\
\hline F 8 & Smix 3 & $1: 2$ & 13.80 & 28.73 & 57.47 & $1: 6.25$ & $1: 0.724$ \\
\hline F 9 & & $1: 2$ & 15.38 & 28.20 & 56.41 & $1: 5.5$ & $1: 0.538$ \\
\hline F 10 & Smix 4 & $1: 2$ & 9.09 & 30.30 & 60.60 & 1:10 & 1:0.818 \\
\hline F 11 & & $1: 2$ & 14.30 & 28.57 & 57.13 & $1: 6$ & $1: 0.428$ \\
\hline F 12 & Smix 5 & 1:1 & 9.09 & 45.45 & 45.45 & $1: 10$ & 1:0.818 \\
\hline F 13 & & 1:1 & 14.30 & 42.85 & 42.85 & $1: 6$ & $1: 0.428$ \\
\hline
\end{tabular}

Precon: pre-concentrate; P.G.: propylene glycol 
potential value of $\pm 30 \mathrm{mV}$ are considered to be stable. Higher the zeta potential, greater will be the energy barrier to coalescence between oil globules and so higher will be the stability of obtained emulsion [25]. SMEDDS F1, F2, F6, F7, F10, and F11 complied with zeta potential requirement for stability (Table 3 and Figs. 9 and 10).

Visual assessment and robustness to dilution

All the SMEDDSs on dilution of up to 100 times with distilled water, 0.1 $\mathrm{N}$ hydrochloric acid, and $\mathrm{pH} 6.8$ buffer and on storage up to $24 \mathrm{~h}$ did not show any sign of phase separation, turbidity, and drug precipitation though SMEDDS F7, F8, and F9 were transparent to slightly bluish only after $24 \mathrm{~h}$ (Table 5). F7-F9 can still be categorized as Grade I emulsion, but since they had shown a tendency to turn slightly bluish and as they contained a high

Table 2: Emulsification time of different bambuterol SMEDDS

\begin{tabular}{ll}
\hline Preconcentrate & Time taken for dispersion \\
\hline F1 & $\leq 10 \mathrm{~s}$ \\
F2 & $\leq 10 \mathrm{~s}$ \\
F3 & $\leq 10 \mathrm{~s}$ \\
F4 & $\leq 10 \mathrm{~s}$ \\
F5 & $\leq 10 \mathrm{~s}$ \\
F6 & $\leq 10 \mathrm{~s}$ \\
F7 & $\leq 10 \mathrm{~s}$ \\
F8 & $\leq 10 \mathrm{~s}$ \\
F9 & $\leq 10 \mathrm{~s}$ \\
F10 & $\leq 10 \mathrm{~s}$ \\
F11 & $\leq 10 \mathrm{~s}$ \\
F12 & $\leq 10 \mathrm{~s}$ \\
F13 & $\leq 10 \mathrm{~s}$ \\
\hline
\end{tabular}

Table 3: Globule size, zeta potential, and PDI of bambuterol SMEDDS in distilled water

\begin{tabular}{llll}
\hline Preconcentrate & $\begin{array}{l}\text { Globule } \\
\text { size }(\mathbf{n m})\end{array}$ & $\begin{array}{l}\text { Zeta potential } \\
(\mathbf{m V})\end{array}$ & PDI \\
\hline F1 & 24.1 & 1.65 & 0.314 \\
F2 & 39.8 & -8.44 & 0.359 \\
F3 & 1241.3 & -0.75 & 0.521 \\
F4 & 37.9 & 1.41 & 0.237 \\
F5 & 14.5 & 0.30 & 0.220 \\
F6 & 751.5 & 6.96 & 0.323 \\
F7 & 22.1 & 0.22 & 0.32 \\
F8 & 84.4 & 26.7 & 0.567 \\
F9 & 1059.3 & 4.97 & 0.455 \\
F10 & 24.4 & -0.17 & 0.119 \\
F11 & 20.7 & 0.09 & 0.389 \\
F12 & 599.4 & 2.63 & 0.286 \\
F13 & 539.3 & -0.52 & 0.250 \\
\hline
\end{tabular}

PDI: Polydispersity index

Table 4: Globule size and poly dispersity index of bambuterol SMEDDS in $0.1 \mathrm{~N} \mathrm{HCl}$

\begin{tabular}{lll}
\hline Preconcentrate & Globule size $(\mathbf{n m})$ & PDI \\
\hline F1 & 39.93 & 0.203 \\
F2 & 16.6 & 0.421 \\
F3 & 14 & 0.075 \\
F4 & 21.4 & 0.047 \\
F5 & 20.7 & 0.050 \\
F6 & 16.8 & 0.084 \\
F7 & 38.4 & 0.268 \\
F8 & 69.9 & 0.048 \\
F9 & 42.2 & 1.783 \\
F10 & 29.7 & 0.050 \\
F11 & 56.8 & 1.783 \\
F12 & 82.6 & 0.411 \\
F13 & 89.1 & 0.232 \\
\hline PDI Polydispersity index & &
\end{tabular}

amount of ethanol, therefore, other formulations were preferred over F7-F9. The clarity of the dispersion may be due to the presence of higher percentage of surfactant as compared to oil. The studies were done in triplicate.

The SMEDDS was graded as Grades I-IV on basis of visual assessment. Table 6 specifies the grading of the emulsion depending on their physical appearance based on visual assessment of the microemulsion formed on dilution. Since all the SMEDDS formed clear emulsion spontaneously and were also robust to dilution, the SMEDDS was categorized as Grade I.

\section{Cloud point test}

Cloud point is an important parameter to assess the stability of the formulations. The cloud point is the temperature above which there is sudden appearance of cloudiness, and this cloudiness is due to the precipitation or phase separation of the drug or any other excipient from the microemulsion formed from the SMEDDS. Higher cloud point indicates greater stability of the SMEDDS during shelf life. In general, the cloud point of the formulations should be above body temperature $\left(37^{\circ} \mathrm{C}\right)[26]$. All the SMEDDSs (F1-F13) when subjected to cloud point test did not show any sign of cloudiness even at high temperatures. Hence, it can be inferred that the formulations will be stable at physiological $\mathrm{pH}$ without the risk of phase separation (Table 7). The studies were done in triplicate.

Percentage transmission/optical clarity

Optical clarity was determined by measuring the percentage transmission of the SMEDDS diluted with distilled water at $400 \mathrm{~nm}$.

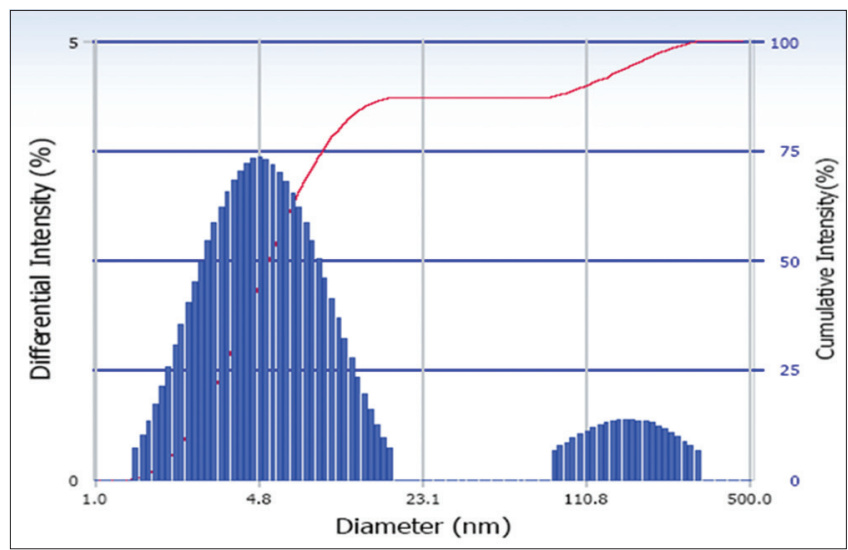

Fig. 9: Zetasizer report of self-microemulsifying drug delivery system F1 in distilled water

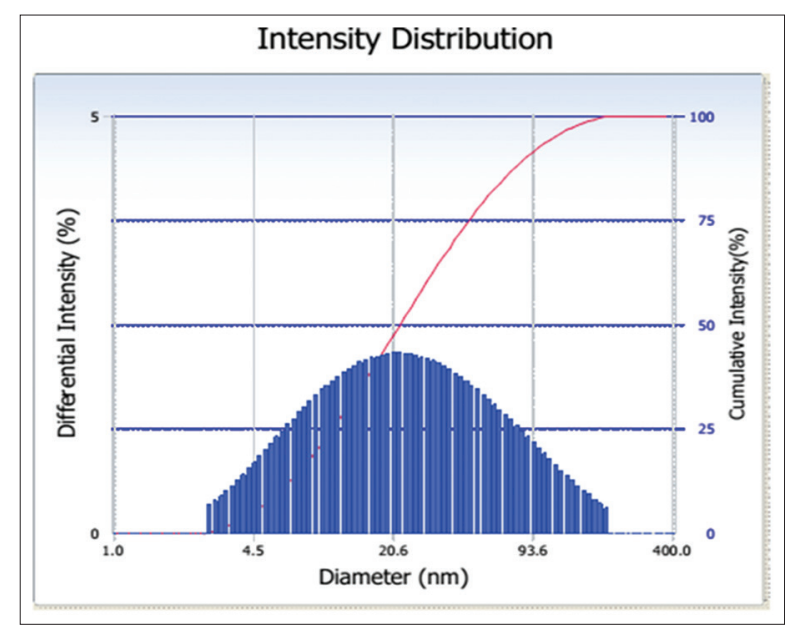

Fig. 10: Zetasizer report of self-microemulsifying drug delivery system F10 in distilled water 
Table 5: Result of robustness to dilution of bambuterol SMEDDS

\begin{tabular}{|c|c|c|c|c|c|c|c|c|c|}
\hline \multirow[t]{2}{*}{ Preconcentrate } & \multicolumn{3}{|c|}{ Distilled water } & \multicolumn{3}{|c|}{$0.1 \mathrm{~N} \mathrm{HCl}$} & \multicolumn{3}{|c|}{ pH 6.8 buffer } \\
\hline & $\mathbf{O h}$ & $12 \mathrm{~h}$ & $24 \mathrm{~h}$ & $\mathbf{O} \mathbf{h}$ & $12 \mathrm{~h}$ & $24 \mathrm{~h}$ & $\mathbf{O h}$ & $12 \mathrm{~h}$ & $24 \mathrm{~h}$ \\
\hline F1 & $\mathrm{T}$ & $\mathrm{T}$ & $\mathrm{T}$ & $\mathrm{T}$ & $\mathrm{T}$ & $\mathrm{T}$ & $\mathrm{T}$ & $\mathrm{T}$ & $\mathrm{T}$ \\
\hline F2 & $\mathrm{T}$ & $\mathrm{T}$ & $\mathrm{T}$ & $\mathrm{T}$ & $\mathrm{T}$ & $\mathrm{T}$ & $\mathrm{T}$ & $\mathrm{T}$ & $\mathrm{T}$ \\
\hline F3 & $\mathrm{T}$ & $\mathrm{T}$ & $\mathrm{T}$ & $\mathrm{T}$ & $\mathrm{T}$ & $\mathrm{T}$ & $\mathrm{T}$ & $\mathrm{T}$ & $\mathrm{T}$ \\
\hline F4 & $\mathrm{T}$ & $\mathrm{T}$ & $\mathrm{T}$ & $\mathrm{T}$ & $\mathrm{T}$ & $\mathrm{T}$ & $\mathrm{T}$ & $\mathrm{T}$ & $\mathrm{T}$ \\
\hline F5 & $\mathrm{T}$ & $\mathrm{T}$ & $\mathrm{T}$ & $\mathrm{T}$ & $\mathrm{T}$ & $\mathrm{T}$ & $\mathrm{T}$ & $\mathrm{T}$ & $\mathrm{T}$ \\
\hline F6 & $\mathrm{T}$ & $\mathrm{T}$ & $\mathrm{T}$ & $\mathrm{T}$ & $\mathrm{T}$ & $\mathrm{T}$ & $\mathrm{T}$ & $\mathrm{T}$ & $\mathrm{T}$ \\
\hline F7 & $\mathrm{T}$ & $\mathrm{T}$ & $\mathrm{T}$ & $\mathrm{T}$ & $\mathrm{T}$ & $\mathrm{T}$ & $\mathrm{T}$ & $\mathrm{T}$ & $\mathrm{T} /$ slight bluish \\
\hline F8 & $\mathrm{T}$ & $\mathrm{T}$ & $\mathrm{T}$ & $\mathrm{T}$ & $\mathrm{T}$ & $\mathrm{T}$ & $\mathrm{T}$ & $\mathrm{T}$ & $\mathrm{T} /$ slight bluish \\
\hline F9 & $\mathrm{T}$ & $\mathrm{T}$ & $\mathrm{T}$ & $\mathrm{T}$ & $\mathrm{T}$ & $\mathrm{T}$ & $\mathrm{T}$ & $\mathrm{T}$ & $\mathrm{T} /$ slight bluish \\
\hline F10 & $\mathrm{T}$ & $\mathrm{T}$ & $\mathrm{T}$ & $\mathrm{T}$ & $\mathrm{T}$ & $\mathrm{T}$ & $\mathrm{T}$ & $\mathrm{T}$ & $\mathrm{T}$ \\
\hline F11 & $\mathrm{T}$ & $\mathrm{T}$ & $\mathrm{T}$ & $\mathrm{T}$ & $\mathrm{T}$ & $\mathrm{T}$ & $\mathrm{T}$ & $\mathrm{T}$ & $\mathrm{T}$ \\
\hline F12 & $\mathrm{T}$ & $\mathrm{T}$ & $\mathrm{T}$ & $\mathrm{T}$ & $\mathrm{T}$ & $\mathrm{T}$ & $\mathrm{T}$ & $\mathrm{T}$ & $\mathrm{T} /$ slight bluish \\
\hline F13 & $\mathrm{T}$ & $\mathrm{T}$ & $\mathrm{T}$ & $\mathrm{T}$ & $\mathrm{T}$ & $\mathrm{T}$ & $\mathrm{T}$ & $\mathrm{T}$ & $\mathrm{T} /$ slight bluish \\
\hline
\end{tabular}

T: Transparent, HCl: Hydrochloric acid, SMEDDS: Self-microemulsifying drug delivery system

Table 6: Grading of bambuterol SMEDDS based on the visual assessment

\begin{tabular}{ll}
\hline Appearance & Grade \\
\hline Clear to slightly bluish Emulsion & Grade I \\
Bluish emulsion & Grade II \\
Bluish to slightly white emulsion & Grade III \\
White or milky emulsion & Grade IV \\
\hline
\end{tabular}

SMEDDS: Self-microemulsifying drug delivery system

Table 7: Result of cloud point test of bambuterol SMEDDS

\begin{tabular}{ll}
\hline Preconcentrate & Observation \\
\hline F1 & No sign of cloudiness/clear solution \\
F2 & No sign of cloudiness/clear solution \\
F3 & No sign of cloudiness/clear solution \\
F4 & No sign of cloudiness/clear solution \\
F5 & No sign of cloudiness/clear solution \\
F6 & No sign of cloudiness/clear solution \\
F7 & No sign of cloudiness/clear solution \\
F8 & No sign of cloudiness/clear solution \\
F9 & No sign of cloudiness/clear solution \\
F10 & No sign of cloudiness/clear solution \\
F11 & No sign of cloudiness/clear solution \\
F12 & No sign of cloudiness/clear solution \\
F13 & No sign of cloudiness/clear solution \\
\hline
\end{tabular}

SMEDDS: Self-microemulsifying drug delivery system

Optical clarity is also the measure of droplet stability, and any significant change in optical clarity on storage indicates droplet instability. The results of the optical clarity test are reported in Table 8 ( $p<0.05$, t-test). It was found that there is negligible change in transmission of light over $24 \mathrm{~h}$ for all the SMEDDSs. The result of the optical clarity test, when read along with results of robustness to dilution test, indicates that all the SMEDDSs are not only stable to dilution, but the droplets formed on dilution are also stable for $24 \mathrm{~h}$. The measurements were done in triplicate.

\section{Refractive index}

The results of the refractive index of the preconcentrate loaded with drug and preconcentrate without drug for all the 13 SMEDDSs show that there was very negligible change in the refractive index of the system (Table 9). Therefore, it can be concluded that SMEDDS is not only thermodynamically stable but also chemically stable, and there was no chemical reaction between excipients and the drug.

\section{Viscosity}

The viscosity of the SMEDDS can affect the rate of absorption. The viscosity of the SMEDDS containing Tween 80 and PG as Smix,
Table 8: Results of the optical clarity test of bambuterol SMEDDS

\begin{tabular}{llll}
\hline Preconcentrate & \multicolumn{3}{l}{ Percentage transmission } \\
\cline { 2 - 4 } & $\mathbf{0 ~ h}$ & $\mathbf{1 2} \mathbf{~}$ & $\mathbf{2 4} \mathbf{~ h}$ \\
\hline F1 & $97 \pm 0.7211$ & $98 \pm 0.2$ & $97.4 \pm 0.529$ \\
F2 & $97 \pm 0.7211$ & $97.3 \pm 0.557$ & $97.1 \pm 0.557$ \\
F3 & $97.1 \pm 0.625$ & $97.6 \pm 0.4$ & $97.4 \pm 0.529$ \\
F4 & $96.5 \pm 0.5$ & $96.6 \pm 0.4$ & $96.3 \pm 0.529$ \\
F5 & $96.3 \pm 0.458$ & $96.3 \pm 0.608$ & $95.7 \pm 0.721$ \\
F6 & $95.6 \pm 0.360$ & $95.7 \pm 0.4$ & $95.7 \pm 0.3$ \\
F7 & $99 \pm 0.265$ & $98.3 \pm 0.4$ & $97.4 \pm 0.3$ \\
F8 & $99 \pm 0.360$ & $98.1 \pm 0.4$ & $97 \pm 0.556$ \\
F9 & $99 \pm 0.2$ & $98.3 \pm 0.3$ & $97.7 \pm 0.4$ \\
F10 & $98.2 \pm 0.265$ & $98.7 \pm 0.173$ & $98.5 \pm 0.265$ \\
F11 & $99.3 \pm 0.173$ & $99 \pm 0.173$ & $98.4 \pm 0.173$ \\
F12 & $97.5 \pm 0.360$ & $96.2 \pm 0.360$ & $95.4 \pm 0.265$ \\
F13 & $97.3 \pm 0.360$ & $96.1 \pm 0.360$ & $95.7 \pm 0.265$ \\
\hline
\end{tabular}

Mean of three measurements \pm SD $(n=3)$,

SMEDDS: Self-microemulsifying drug delivery system

Table 9: Result of refractive index of blank and drug-loaded bambuterol SMEDDS

\begin{tabular}{lll}
\hline Preconcentrate & \multicolumn{2}{l}{ Refractive Index } \\
\cline { 2 - 3 } & Blank & Drug-loaded SMEDDS \\
\hline F1 & $1.410 \pm 0.011$ & $1.389 \pm 0.011$ \\
F2 & $1.399 \pm 0.014$ & $1.420 \pm 0.017$ \\
F3 & $1.410 \pm 0.012$ & $1.422 \pm 0.009$ \\
F4 & $1.427 \pm 0.008$ & $1.416 \pm 0.007$ \\
F5 & $1.423 \pm 0.019$ & $1.417 \pm 0.010$ \\
F6 & $1.426 \pm 0.008$ & $1.416 \pm 0.014$ \\
F7 & $1.381 \pm 0.009$ & $1.390 \pm 0.005$ \\
F8 & $1.380 \pm 0.009$ & $1.390 \pm 0.006$ \\
F9 & $1.382 \pm 0.010$ & $1.384 \pm 0.011$ \\
F10 & $1.423 \pm 0.013$ & $1.426 \pm 0.016$ \\
F11 & $1.422 \pm 0.007$ & $1.426 \pm 0.007$ \\
F12 & $1.429 \pm 0.012$ & $1.432 \pm 0.016$ \\
F13 & $1.429 \pm 0.005$ & $1.433 \pm 0.006$ \\
\hline
\end{tabular}

Mean of three measurements \pm SD $(n=3)$.

SMEDDS: Self-microemulsifying drug delivery system

i.e., F10-13 was more than those SMEDDS containing Tween 80 and ethanol as Smix, i.e., F1-9. Further, the viscosity of the SMEDDS increased with an increase in content of Tween 80 , and the viscosity of formulation containing Smix in ratio of 2:1 was more than the viscosity of formulation containing Smix in ratio 1:1 which was greater than formulation containing Smix in ratio 1:2, i.e., viscosity of F4-6 > F1-3 > F6-9 (Table 10). From the viscosity studies, it was observed that the nature and concentration of the surfactant and cosurfactant affect the 
viscosity of the SMEDDS. The viscosity measurements were done in triplicate.

\section{Drug content}

Irrespective of the concentration of oil, surfactant, and cosurfactant, the drug content in the 13 formulations was found to be in the range of $94.37-102.49 \%$ ( $p<0.05, t$-test), indicating uniform dispersion of the drug in the SMEDDS (Table 11). The drug content of the samples was determined in triplicate.

Table 10: Viscosity of various bambuterol SMEDDS

\begin{tabular}{llll}
\hline Preconcentrate & \multicolumn{2}{l}{ Viscosity (cp) } & \\
\cline { 2 - 4 } & $\mathbf{2} \mathbf{~ r p m}$ & $\mathbf{6} \mathbf{~ r p m}$ & $\mathbf{1 2} \mathbf{~ r p m}$ \\
\hline F1 & $928 \pm 17.44$ & $330 \pm 3.6$ & $208 \pm 3.46$ \\
F2 & $903 \pm 6.08$ & $325 \pm 4.58$ & $196 \pm 2.65$ \\
F3 & $940 \pm 10.15$ & $350 \pm 2.65$ & $188 \pm 7.00$ \\
F4 & $900 \pm 8.54$ & $337 \pm 2.0$ & $208 \pm 6.08$ \\
F5 & $1018 \pm 14.73$ & $363 \pm 4.58$ & $208 \pm 3.0$ \\
F6 & $1000 \pm 4.58$ & $378 \pm 6.56$ & $210 \pm 1.0$ \\
F7 & $888 \pm 8.0$ & $330 \pm 4.58$ & $179 \pm 3.60$ \\
F8 & $895 \pm 5.57$ & $330 \pm 5.0$ & $189 \pm 2.0$ \\
F9 & $967 \pm 7.0$ & $346 \pm 3.60$ & $194 \pm 2.64$ \\
F10 & $1050 \pm 9.0$ & $401 \pm 3.60$ & $251 \pm 4.58$ \\
F11 & $1060 \pm 9.64$ & $401 \pm 7.0$ & $237 \pm 2.0$ \\
F12 & $1121 \pm 10.26$ & $457 \pm 8.0$ & $296 \pm 5.57$ \\
F13 & $1110 \pm 12.52$ & $433 \pm 6.25$ & $300 \pm 3.0$ \\
\hline
\end{tabular}

Mean of three measurements \pm SD $(n=3)$,

SMEDDS: Self-microemulsifying drug delivery system

Table 11: Drug content of 13 SMEDDS formulations of bambuterol

\begin{tabular}{ll}
\hline Preconcentrate & Percentage drug content \\
\hline F1 & $97.27 \pm 0.62$ \\
F2 & $94.37 \pm 0.96$ \\
F3 & $102.49 \pm 1.54$ \\
F4 & $96.38 \pm 1.37$ \\
F5 & $98.05 \pm 1.63$ \\
F6 & $98.23 \pm 0.76$ \\
F7 & $99.15 \pm 1.38$ \\
F8 & $100.00 \pm 1.07$ \\
F9 & $98.79 \pm 0.005$ \\
F10 & $99.62 \pm 1.39$ \\
F11 & $99.56 \pm 1.26$ \\
F12 & $99.16 \pm 2.00$ \\
F13 & $100.61 \pm 1.48$ \\
\hline
\end{tabular}

Mean of three measurements \pm SD $(n=3)$,

SMEDDS: Self-microemulsifying drug delivery system
Stability studies

The physical stability of a lipid-based formulation is also crucial to its performance, which can be adversely affected by precipitation of the drug in the excipient matrix. Physical instability can lead to phase separation of the excipient and active ingredients, affecting not only formulation performance but also visual appearance as well

Preconcentrate containing $10 \mathrm{mg}$ of the drug, bambuterol hydrochloride, was diluted with distilled water to form $5 \mathrm{~g}$ formulation. Correspondingly, preconcentrate without drug was also diluted with distilled water to form $5 \mathrm{~g}$ formulation and stored at room temperature and conditions and studied for 6 months. The dilution was done as per the ratios of all the three components (oil, Smix, and water) (Table 1) obtained from the phase diagram. Results tabulated in Table 12 show that there was no phase separation, precipitation of the drug, or any other excipients.

Likewise, preconcentrate loaded with drug and preconcentrate without drug were stored at room temperature for 6 months. Results tabulated in Table 13 shows that there was no phase separation, precipitation of the drug, or any other excipients. Thus, it can be concluded that both the SMEDDS and microemulsions are stable under room conditions.

\section{Thermodynamic stability studies}

Heating and cooling cycle/stability testing: All the 13 formulations (preconcentrate containing $10 \mathrm{mg}$ of the drug, bambuterol hydrochloride, diluted with distilled water to form $5 \mathrm{~g}$ formulation) did not show any sign of drug precipitation, phase separation, or turbidity when subjected to six cycles of heating and cooling. These formulations were then subjected to centrifuge test.

\section{Centrifuge test}

All the formulations, [F1-F13], were found to stable and passed the centrifuge test as phase separation was not observed. Results are tabulated in Table 14

\section{Comparative ex vivo intestinal permeability studies}

Diffusion profile of SMEDDS F1 and F10 was compared with the diffusion profile of drug dissolved in distilled water. After $2 \mathrm{~h}, 16.17 \pm 0.26 \%$ of the drug diffused from the SMEDDS F1 and $12.06 \pm 0.26 \%$ of the drug diffused from SMEDDS F10, whereas from the plain drug solution, the diffusion was found to be $10.02 \pm 0.35 \%$ ( $\mathrm{p}<0.05$, t-test). After $2 \mathrm{~h}$, the amount of drug diffusing out of SMEDDS F1 was 1.6 times more as compared to plain bambuterol solution, whereas the amount of drug diffusing out of SMEDDS F10 was 1.2 times more as compared to bambuterol solution. The drug diffused at a faster rate from SMEDDS F1 as compared to SMEDDS F10 and plain drug (Table 15 and Fig. 11) due to increased permeability of the drug across the intestine. This may be attributed to the fact that the presence of alcohol affects the physical properties of water. Ethanol disrupts the water structure, creating an increase in the lipophilic character of Tween

Table 12: Result of stability studies of bambuterol microemulsion at room temperature

\begin{tabular}{|c|c|c|c|c|}
\hline \multirow[t]{2}{*}{ Formulation } & \multicolumn{2}{|c|}{ Formulation without drug } & \multicolumn{2}{|c|}{ Formulation with drug } \\
\hline & 3 months & 6 months & 3 months & 6 months \\
\hline F1 & No phase separation & No phase separation & No phase separation & No phase separation \\
\hline F3 & No phase separation & No phase separation & No phase separation & No phase separation \\
\hline $\mathrm{F} 4$ & No phase separation & No phase separation & No phase separation & No phase separation \\
\hline F5 & No phase separation & No phase separation & No phase separation & No phase separation \\
\hline F6 & No phase separation & No phase separation & No phase separation & No phase separation \\
\hline F7 & No phase separation & No phase separation & No phase separation & No phase separation \\
\hline F8 & No phase separation & No phase separation & No phase separation & No phase separation \\
\hline F9 & No phase separation & No phase separation & No phase separation & No phase separation \\
\hline F10 & No phase separation & No phase separation & No phase separation & No phase separation \\
\hline F11 & No phase separation & No phase separation & No phase separation & No phase separation \\
\hline F12 & No phase separation & No phase separation & No phase separation & No phase separation \\
\hline F13 & No phase separation & No phase separation & No phase separation & No phase separation \\
\hline
\end{tabular}


Table 13: Result of stability studies for bambuterol SMEDDS at room temperature

\begin{tabular}{|c|c|c|c|c|}
\hline \multirow[t]{2}{*}{ Preconcentrate } & \multicolumn{2}{|c|}{ Preconcentrate without drug } & \multicolumn{2}{|c|}{ Preconcentrate with drug } \\
\hline & 3 months & 6 months & 3 months & 6 month \\
\hline F1 & No phase separation & No phase separation & No phase separation & No phase separation \\
\hline F3 & No phase separation & No phase separation & No phase separation & No phase separation \\
\hline F4 & No phase separation & No phase separation & No phase separation & No phase separation \\
\hline F5 & No phase separation & No phase separation & No phase separation & No phase separation \\
\hline F6 & No phase separation & No phase separation & No phase separation & No phase separation \\
\hline F7 & No phase separation & No phase separation & No phase separation & No phase separation \\
\hline F8 & No phase separation & No phase separation & No phase separation & No phase separation \\
\hline F9 & No phase separation & No phase separation & No phase separation & No phase separation \\
\hline F10 & No phase separation & No phase separation & No phase separation & No phase separation \\
\hline F11 & No phase separation & No phase separation & No phase separation & No phase separation \\
\hline F12 & No phase separation & No phase separation & No phase separation & No phase separation \\
\hline F13 & No phase separation & No phase separation & No phase separation & No phase separation \\
\hline
\end{tabular}

SMEDDS: Self-microemulsifying drug delivery system

Table 14: Result of heating and cooling cycle and centrifuge test of bambuterol formulations

\begin{tabular}{|c|c|c|c|}
\hline \multirow[t]{2}{*}{ Formulation } & \multicolumn{3}{|l|}{ Observations } \\
\hline & Precipitation & Phase separation & Turbidity \\
\hline $\mathrm{F} 1$ & $\mathrm{x}$ & $\mathrm{x}$ & $\mathrm{x}$ \\
\hline $\mathrm{F} 2$ & $\mathrm{x}$ & $\mathrm{x}$ & $\mathrm{x}$ \\
\hline F3 & $\mathrm{x}$ & $\mathrm{x}$ & $\mathrm{x}$ \\
\hline $\mathrm{F} 4$ & $\mathrm{x}$ & $\mathrm{x}$ & $\mathrm{x}$ \\
\hline F5 & $\mathrm{x}$ & $\mathrm{x}$ & $\mathrm{x}$ \\
\hline F6 & $\mathrm{x}$ & $\mathrm{x}$ & $\mathrm{x}$ \\
\hline F7 & $\mathrm{x}$ & $\mathrm{x}$ & $\mathrm{x}$ \\
\hline F8 & $\mathrm{x}$ & $\mathrm{x}$ & $\mathrm{x}$ \\
\hline F9 & $\mathrm{x}$ & $\mathrm{x}$ & $\mathrm{x}$ \\
\hline F10 & $\mathrm{x}$ & $\mathrm{x}$ & $\mathrm{x}$ \\
\hline F11 & $\mathrm{x}$ & $\mathrm{x}$ & $\mathrm{x}$ \\
\hline F12 & $\mathrm{x}$ & $\mathrm{x}$ & $\mathrm{x}$ \\
\hline F13 & $\mathrm{x}$ & $\mathrm{x}$ & $\mathrm{x}$ \\
\hline
\end{tabular}

Table 15: Percentage cumulative drug permeability (ex vivo) of pure drug solution, F1, and F10 SMEDDS of bambuterol

\begin{tabular}{llll}
\hline $\begin{array}{l}\text { Time in } \\
\text { minutes }\end{array}$ & $\begin{array}{l}\text { \% CDP - pure } \\
\text { drug solution }\end{array}$ & \% CDP - F1 & \% CDP - F10 \\
\hline 0 & 0 & 0 & 0 \\
30 & $4.02 \pm 0.13$ & $5.95 \pm 0.17$ & $4.59 \pm 0.13$ \\
60 & $6.87 \pm 0.28$ & $10.79 \pm 0.14$ & $8.05 \pm 0.14$ \\
90 & $8.99 \pm 0.21$ & $13.77 \pm 0.23$ & $10.71 \pm 0.086$ \\
120 & $10.02 \pm 0.35$ & $16.26 \pm 0.26$ & $12.06 \pm 0.26$ \\
\hline
\end{tabular}

Mean of three measurements \pm SD $(n=3)$.

\%CDP: Percentage cumulative drug permeability

$80[33,34]$. Further ethanol provokes a decrease in mixture viscosity [35]; therefore, Tween 80 can reach the interface faster.

\section{CONCLUSION}

In this study, SMEDDS of a drug having poor bioavailability, bambuterol hydrochloride was formulated successfully by ultrasonication method for oral administration. Components of the SMEDDS formulation and their ratios were obtained by solubility studies and pseudo ternary phase diagram. The SMEDDS formulations were assessed for globule size, emulsification time, zeta potential, robustness on dilution, light transmission, viscosity, drug content and loading, stability, and ex vivo permeability.

The formulation F1 containing $10 \mathrm{mg}$ bambuterol hydrochloride, triacetin $(12.50 \% \mathrm{w} / \mathrm{w})$, Tween $80(43.75 \% \mathrm{w} / \mathrm{w})$, and ethanol $(43.75 \% \mathrm{w} / \mathrm{w})$ was concluded to be optimum. The optimized SMEDDS

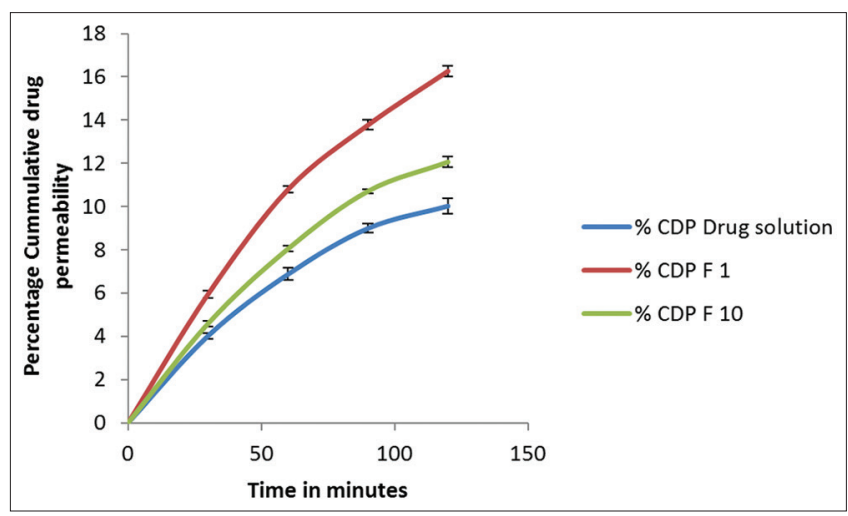

Fig. 11: Graph of percentage cumulative drug permeability against time for drug solution, F1 and F10 SMEDDS of bambuterol (mean $\pm S D ; n=3$ )

not only showed optimum globule size, zeta potential, and drug content but was also found to be robust to dilution, forms emulsion spontaneously, and was stable. The optimized SMEDDS showed increased permeability of the drug across the intestinal membrane when compared with plain drug solution and formulation F10, in ex vivo studies.

The results suggest that bambuterol hydrochloride can be formulated as self-microemulsifying drug delivery system and further SMEDDS can be used to improve the oral bioavailability of bambuterol hydrochloride.

\section{ACKNOWLEDGMENT}

The authors are thankful to Chandigarh University, Mohali, Punjab, and Gyani Inder Singh Institute of Professional Studies, Dehradun, for providing the necessary facilities for carrying out the studies and experiments.

\section{AUTHOR'S CONTRIBUTION}

The manuscript is original research carried out by Sachin Saggar and is a part of his Ph.D. degree research work, under the guidance of Prof. (Dr.) Ashutosh Upadhayay and Prof. (Dr.) Manish Goswami.

\section{CONFLICTS OF INTEREST}

The authors declared that they have no conflicts of interest.

\section{REFERENCES}

1. Pouton CW. Formulation of poorly water-soluble drugs for oral administration: Physicochemical and physiological issues and the lipid formulation classification system. Eur J Pharm Sci 2006;29:278-87. 
2. Constantinides PP. Lipid microemulsions for improving drug dissolution and oral absorption: Physical and biopharmaceutical aspects. Pharm Res 1995;12:1562-72.

3. Gershanik T, Benita S. Self-dispersing lipid formulations for improving oral absorption of lipophilic drugs. Eur J Pharm Biopharm 2000;50:179-88.

4. Gursoy RN, Benita S. Self-emulsifying drug delivery systems (SEDDS) for improved oral delivery of lipophilic drugs. Biome Pharmacother 2004;58:173-82.

5. Đekić L, Primorac M. Microemulsion and Nanoemulsions as Carrier for Delivery of NSAIDS: Formulation Challenges and Potential Benefits. Cambridge, MA: Academic Press; 2017. p. 69-94.

6. Pouton CW. SEDDS: Assessment of the efficiency of emulsification. Int J Pharm 1985;27:335-48.

7. Shah NH, Carvajal MT, Patel CI, Infeld MH, Malick AW. Selfemulsifying drug delivery systems (SEDDS) with poly glycolyzed glycerides for improving in vitro dissolution and oral absorption of lipophillic drugs. Int J Pharm 1994;106:15-23.

8. Chitneni M, Peh KK, Darwis D, Abdulkarim M, Abdullah GZ, Qureshi MJ, et al. Intestinal permeability studies of sulpiride incorporated into self-microemulsifying drug delivery system (SMEDDS). Pak J Pharm Sci 2011;24:113-21.

9. Wasan KM. Drug Dev Ind Pharm 2001;27:267-76.

10. Serajuddin AT, Sheen PC, Mufson D, Bernstein DF, Augustine MA. Effect of vehicle amphiphilicity on the dissolution and bioavailability of a poorly water-soluble drug from solid dispersions. J Pharm Sci 1988;77:414-7.

11. Porter CJ, Pouton CW, Cuine JF, Charman WN. Enhancing intestinal drug solubilisation using lipid-based delivery systems. Adv Drug Deliv Rev 2008;60:673-91

12. Porter CJ, Charman WN. In vitro assessment of oral lipid based formulations. Adv Drug Deliv Rev 2001;50 Suppl 1:S127-47.

13. Chen ML. Lipid excipients and delivery systems for pharmaceutical development: A regulatory perspective. Adv Drug Deliv Rev 2008;60:768-77.

14. Stationary Office Books. The British Pharmacopoeia. Vol. 1. London: Stationary Office Books; 2001.

15. Rosenborg J, Larsson P, Nyberg L. Pharmacokinetics of bambuterol during oral administration of plain tablets and solution to healthy adults. Br J Clin Pharmacol Mar 2000;49:199-206.

16. Nyberg L, Rosenborg J, Weibull E, Nilsson M, Jönsson S, Kennedy B. Pharmacokinetics of bambuterol in healthy subjects. $\mathrm{Br} \mathrm{J}$ Clin Pharmacol 1998;45:471-8.

17. Sabale V, Vora S. Formulation and evaluation of microemulsion-based hydrogel for topical delivery. Int J Pharm Investig 2012;2:140-9.

18. Gaikwad S, Godbole M, Potnis V, Daud A. Formulation and evaluation of self-emulsifying drug delivery system of orlistat. Am J PharmTech Res 2012;2:297-311

19. Jaiswal P, Aggarwal G, Harikumar SL, Singh K. Development of self-microemulsifying drug delivery system and solid-selfmicroemulsifying drug delivery system of telmisartan. Int J Pharm Investig 2014;4:195-206.
20. Deshmukh A, Kulkarni S. Novel self-micro-emulsifying drug delivery system (SMEDDS) of efavirez. J Chem Pharm Res 2012;4:3914-19.

21. Modi J. Formulation and evaluation of nanoemulsion based drug delivery of NSAIDS. Int J Pharm Pharm Sci Res 2012;1:6-12.

22. Ahmad J, Amin S, Hohli K, Mir SR. Construction of pseudoternary phase diagram and its evaluation: Development of dispersible oral formulation. Int J Drug Dev Res 2013;5:84-90.

23. Syed HK, Peh KK. Identification of phases of various oil, surfactant/cosurfactants and water system by ternary phase diagram. Acta Poloniae Pharm Drug Res 2014;71:301-9.

24. Prajapati S, Joshi H, Patel C. Preparation and characterization of selfmicro-emulsifying drug delivery system of olmesartan medoxomil for bioavailability improvement. J Pharm 2013;Article ID: 728425, 9 Pages.

25. Kasturi M, Aggrawal S, Jadav JK. Self nanoemulsifying drug delivery sytem of ramipril formulation and in vitro evaluation. Int $\mathrm{J}$ Pharm Pharm Sci 2016;8:291-6.

26. Deshmukh SR, Bakhle SS, Upadhye K, Dixit GR. Formulation and evaluation of solid self-emulsifying drug delivery system of gliclazide. Int J Pharm Pharm Sci 2016;8:144-51.

27. Liu W, Pan H, Zhang C, Zhao L, Zhao R, Zhu Y, et al. Developments in methods for measuring the intestinal absorption of nanoparticle-bound drugs. Int J Mol Sci 2016;17:pii: E1171.

28. Waiver of in vivo Bioavailability and Bioequivalence Studies for Immediate-Release Solid Oral Dosage Forms Based on a Biopharmaceutics Classification System: Guidance for Industry: U.S. Department of Health and Human Services Food and Drug Administration Center for Drug Evaluation and Research (CDER); 2017.

29. Jang DJ, Jeong EJ, Lee HM, Kim BC, Lim SJ, Kim CK, et al. Improvement of bioavailability and photostability of amlodipine using redispersible dry emulsion. Eur J Pharm Sci 2006;28:405-11.

30. Nazzal S. Preparation and in vitro characterization of a eutectic based semisolid self-nanoemulsified drug delivery system (SNEDDS) of ubiquinone: Mechanism and progress of emulsion formation. Int $\mathrm{J}$ Pharm 2002;235:247-65.

31. Raval M, Patel J, Patel A, Sheth N. Formulation and development of a self-nanoemulsifying drug delivery system of irbesartan. AAPS J 2011;2:9-16.

32. Charman SA, Charman WN, Rogge MC, Wilson TD, Dutko FJ, Pouton CW. Self-emulsifying drug delivery systems: Formulation and biopharmaceutic evaluation of an investigational lipophilic compound. Pharm Res 1992;9:87-93.

33. Prieto C, Calvo L. Performance of the biocompatible surfactant tween 80, for the formulation of microemulsions suitable for new pharmaceutical processing. J Appl Chem 2013;Article ID 930356, 10 Pages.

34. Reekmans S, Luo H, Van Der Auweraer M, De Schryver FC. Influence of alcohols and alkanes on the aggregation behavior of ionic surfactants in wate. Langmuir 1990;6:628-37.

35. Bayrak Y, Iscan M. Studies on the phase behavior of the system non-ionic surfactant/alcohol/alkane/H2O/. Colloids Surfaces A 2005;268:99-103. 